\title{
Epidemiological Profile of Chronic Hemodialysis Patients in Ouagadougou
}

\author{
Coulibaly Gérard*, Da Sami Augustin, Karambiri Adama Roger, Lengani M. H. Aïda, \\ Sanou Gaoussou, K. Manan Hien, Lengani Adama \\ Department of Nephrology and Hemodialysis, University Hospital Center Yalgado Ouedraogo (UHC-YO), \\ Ouagadougou, Burkina Faso \\ Email: *coulibalygerard@hotmail.fr
}

Received 7 March 2016; accepted 22 April 2016; published 25 April 2016

Copyright (C) 2016 by authors and Scientific Research Publishing Inc.

This work is licensed under the Creative Commons Attribution International License (CC BY). http://creativecommons.org/licenses/by/4.0/

(c) (i) Open Access

\begin{abstract}
Goal: By describing the epidemiology of chronic hemodialysis patients in the single hemodialysis unit of Burkina Faso, we want to contribute to the prevention and improvement of chronic renal failure management (CRF) in this country. Patients and Methods: A descriptive cross-sectional study was conducted in the hemodialysis unit of the University Hospital Center Yalgado Ouedraogo (UHC-YO) during the period from February 12 to May 15, 2015. The patients who started hemodialysis in this unit and were treated for at least three months were included in this study. The sociodemographic and clinical data were collected. The statistical significance was defined for a probability ( $p \leq 0.05)$. Results: One hundred and seventy-two patients $(71.2 \%$ of the 240 patients of the unit) have been included. The sex ratio was 1.6. The average age was $45.2 \pm 12.4$ years old. The presumed causes of CRF have been identified in 134 cases $(77.9 \%)$. The most frequent were hypertensive nephropathy (65 cases; $48.5 \%$ ), chronic glomerulonephritis (41 cases; $30.6 \%$; including 11 viral origin and 16 with history of recurrent otorhinolaryngologic infections and/or urinary schistosomiasis). Hemodialysis began in an emergency context in 118 cases $(68.6 \%)$. The average duration of hemodialysis was $29.4 \pm 28.4$ months. Conclusion: The main suspected causes of CRF were hypertension and chronic glomerulonephritis. The origin of the latter seemed more often infectious. Prevention of CRF in Burkina Faso should be focused on that of hypertension and infectious diseases.
\end{abstract}

\section{Keywords}

Burkina Faso, Chronic Renal Failure, Epidemiology, Hemodialysis, Yalgado Ouédraogo

\section{Introduction}

The renal replacement therapy is essential for patient survival at the final stage of chronic renal failure (CRF).

${ }^{*}$ Corresponding author.

How to cite this paper: Gérard, C., Augustin, D.S., Roger, K.A., Aïda, L.M.H., Gaoussou, S., Manan Hien, K. and Adama, L. (2016) Epidemiological Profile of Chronic Hemodialysis Patients in Ouagadougou. Open Journal of Nephrology, 6, 29-36. 
Several modalities of this type of treatment exist: renal replacement therapy (hemodialysis or peritoneal dialysis) and kidney transplantation. Hemodialysis is the most commonly used modality in the world [1] [2].

The treatment of end-stage renal disease (ESRD) is expensive, especially in case of hemodialysis [3]. The accessibility to this modality is far better in developed countries than developing countries. In Africa, there is a disparity in accessibility through the reported prevalences. Thus, it was reported in 2015 a prevalence of 400 pmh in North Africa and 12.6 pmh in West Africa [4].

The profile of chronic hemodialysis patients varies from one region of the world to another. This variation is often a reflection of the quality of the comprehensive health care level in each region. Knowing the profile of hemodialysis patients would certainly help in the definition of the areas of prevention of the chronic kidney disease (CKD). If this is effective in developed countries, this is not the case in developing countries where data are still embryonic [4]. Descriptive studies seem so indispensable in this part of the world.

In this study, we wanted to describe the epidemiological profile of chronic hemodialysis patients in the hemodialysis unit of the University Hospital Center Yalgado Ouedraogo (UHC-YO) of Ouagadougou. The goal is to contribute to the prevention and improvement of the CKD management in Burkina Faso.

\section{Patients and Method}

It was a descriptive cross-sectional study from February 12 to May 15, 2015. It was conducted in the hemodialysis unit of the UHC-YO. The latter opened its doors in December 2000. Its initial capacity of nine posts is extended to 29 (divided over two sites within the UHC-YO) starting in 2009. The frequency of hemodialysis sessions at the time of the study was one every five days. It is therefore a serious situation of under-dialysis responsible among others of a high frequency of ascites of great abundance (Figure 1).

The hemodialysis unit with that of the clinical nephrology constituted the department of Nephrology and Hemodialysis of the UHC-YO, the only one of the country at the time of the study. In this second unit, hospitalization of patients and nephrology outpatient consultations were carried out. The medical staff of the department consisted of three nephrologists (including a volunteer of Cuban nationality), a doctor in the last year of specialization in Nephrology, and two general practitioners. The hemodialysis nurses were 23 including two senior health officers in surgery.

The cost of the hemodialysis session was funded by the State. On the other hand; drugs, tests and transportation

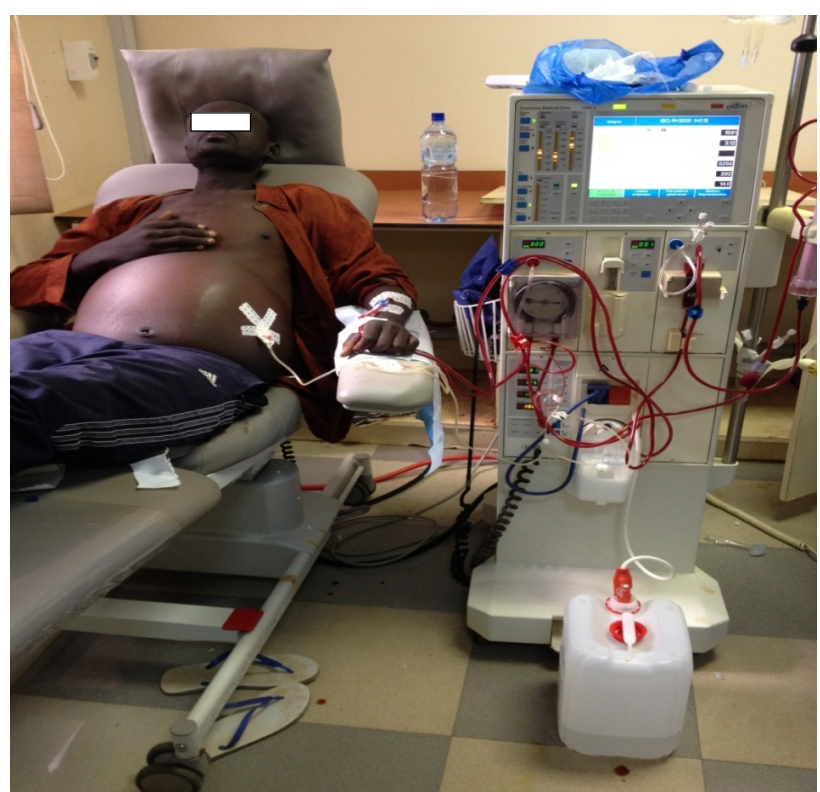

Figure 1. Hemodialysis patient with an abundance of ascites reflecting the sub-dialysis. An ascites puncture is underway. Ascites is fed back into the arterial line during the hemodialysis session, according to the technique of the previous [5] we have adapted by lack of isolated pump for ascites. 
expenses were entirely charged to nearly all hemodialysis patients. There was not yet a generalized health insurance system.

Our study included patients undergoing hemodialysis in the hemodialysis unit of the UHC-YO of Ouagadougou. At the beginning of the data collection period, 240 patients were treated by iterative hemodialysis in the unit. We included in the study 172 patients (71.2\%) according to the following criteria:

- having started hemodialysis in the hemodialysis unit of the UHC-YO;

- and having been treated for at least three months.

We operationally defined some concepts:

- chronic hemodialysis patient was a patient treated by iterative hemodialysis for at least three months for ESRD;

- In the absence of anatomopathological data, the diagnostic criteria for the presumed causes of ESRD relied on clinical, biological and radiological set of evidence of the period before the hemodialysis setting. We thus considered:

$\checkmark \quad$ Chronic glomerulonephritis (CGN): proteinuria greater than $1 \mathrm{~g} / 24 \mathrm{~h}$, with or without hematuria, with or without CRF, with or without small harmonious bilateral kidneys on ultrasound. We included diabetic nephropathy and nephropathy related to HIV;

$\checkmark \quad$ Chronic tubulointerstitial nephritis (CTIN): history of recurrent urinary tract infections, gout, orurolithiasis associated with chronic leukocyturia with or without CRF, long term hydronephrosis, or asymmetric kidneys or with irregular borders on ultrasound;

$\checkmark \quad$ Hypertensive nephropathy: long term hypertension (HTN) with left ventricular hypertrophy on electrocardiogram and hypertensive retinopathy associated to CRF with or without proteinuria $\geq 0.5 \mathrm{~g} / 24$ hours;

$\checkmark \quad$ Polycystic kidney disease (presumed autosomal dominant) according to the modified Ravine's criteria of Pei: three unilateral or bilateral cysts in people over 15-year-old, three cysts by kidney between 40 and 59 years, at least four cysts by kidney after 59 years [6].

The nephropathy was considered unclassifiable when data were insufficient to allow the classification.

The source of data consisted of patient medical records and the individual monitoring notebooks of hemodialysis sessions. We collected sociodemographic data (gender, age, origin, and professional category) personal medical history, data on the vascular approaches for hemodialysis in patients, and duration and mode of entry into hemodialysis.

The data were recorded and analyzed using SPSS software version 17. For the comparison of qualitative variables, we used Chi square and exact Fischer tests. The Student's t test was used for comparison of quantitative variables. The level of statistical significance was set for a probability $\mathrm{p} \leq 0.05$.

This study had a goal of defining the epidemiological profile. It required a clinical examination and a collection of data from patients. The informed consent of patients was required prior to the collection of these data. These have been treated confidentially. The UHC-YO lacked an ethics committee at the time of the study.

\section{Results}

\subsection{Sociodemographic Data}

At the time of the study, the population of Burkina Faso was estimated at 18,450,494 people and that of Ouagadougou at 2,500,000. Were included in this study, 172 hemodialysis patients representing $71.2 \%$ of the 240 patients of the unit at the beginning of the study, 9.3 per million population (pmp) in Burkina Faso and 68.8 pmp in the city of Ouagadougou. They were divided into 66 women (38.4\%) and 106 men (61.6\%), with a sex ratio of 1.6.

The average age of patients was $45.2 \pm 12.4$ years old (extremes $=16$ and 78 ). The average age of men was 41 \pm 14.1 years and that of women was $45.3 \pm 14.2$ years old (extremes $=16$ and 73 ). There was no significant difference in age between men and women $(\mathrm{p}=0.49)$. The overall modal age group was that of 50 to 59 years (Table 1).

The most common level of education was high school (Table 2).

In total 80 patients (45.6\%) were unemployed, farmers or retired.

The patients came from 11 of the 13 regions of the country. The three most frequent regions of origin were: the Centre (107 patients, 62.2\%), the Hauts-Bassins (15 patients, 8.7\%) and the Centre-Est (12 patients, 7\%). No patient was from the Sud-Ouest or Plateau-Central (Figure 2). 
Table 1. Distribution of hemodialysis patients by age and gender.

\begin{tabular}{cccc}
\hline & Male $\mathbf{n}(\mathbf{\%})$ & Female n (\%) & Total n (\%) \\
\hline$<20$ years & $4(3.8)$ & $3(4.6)$ & $7(4.1)$ \\
$20-29$ years & $20(18.9)$ & $10(15.2)$ & $30(17.4)$ \\
$30-39$ years & $26(24.5)$ & $9(13.6)$ & $35(20.3)$ \\
$40-49$ years & $20(18.9)$ & $16(24.2)$ & $36(20.9)$ \\
$50-59$ years & $23(21.7)$ & $15(22.7)$ & $38(22.1)$ \\
$\geq 60$ years & $13(12.2)$ & $13(19.7)$ & $26(15.2)$ \\
Total & $\mathbf{1 0 6}(\mathbf{1 0 0})$ & $\mathbf{6 6}(\mathbf{1 0 0})$ & $\mathbf{1 7 2 ( 1 0 0 )}$ \\
\hline
\end{tabular}

Table 2. Level of education and profession of hemodialysis patients.

\begin{tabular}{cccc}
\hline & Number & Percentage \\
Elementary school & Level of education & & 22.1 \\
Middle and High school & 38 & 35.5 & 18.0 \\
College and university & 61 & 24.4 & 18.6 \\
None & 31 & 9.9 \\
Professional status & 42 & 25.0 \\
Government official & 32 & 8.1 \\
Private company employee & 17 & 30.2 \\
Trader & 43 & 8.1 \\
\hline
\end{tabular}

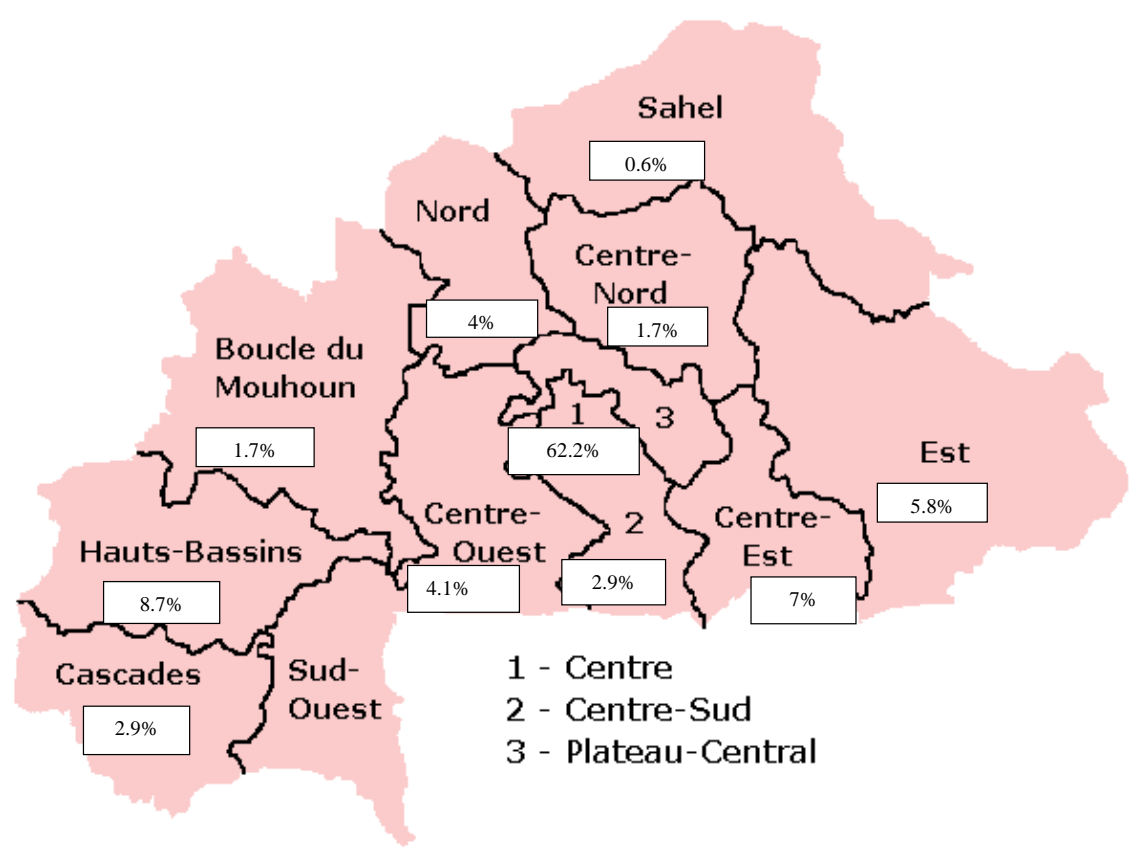

Figure 2. Relative frequency of origin regions of hemodialysis patients in Burkina Faso. 


\subsection{Personal Medical History of Patients}

The patients had a history of known hypertension in 117 cases (68\%), chronic renal failure in 108 cases (62.8\%), and diabetes in 14 cases (8.1\%). The 108 patients with CRF had a nephrology follow-up before hemodialysis for a period of 1 to 205 months (17 years); therefore at least 64 patients (37.2\%) had their first contact with the department at the final stage of CRF.

History of macroscopic hematuria was noted in 38 cases (22.1\%). As infections, we noted: otorhinolaryngologic sphere infections (ORL; 54 cases or 31.4\%), urinary tract infections (53 cases, 30.8\%), urinary schistosomiasis (34 cases, 19.8\%), six cases (3.5\%) of HIV infection and five cases (2.9\%) of viral hepatitis B. Nineteen patients or $11 \%$ had a history of gout. A concept of frequent use of traditional medicines was found in 82 cases (47.7\%).

\subsection{Presumed Cause of ESRD}

The presumed causes couldn't be identified in 38 cases (22.1\%). The 134 remaining cases (77.9\%) were:

- hypertensive nephropathy: 65 cases representing $48.5 \%$ of the 134 ;

- chronic glomerulonephritis: 41 cases (30.6\%) divided into 14 cases related to diabetes representing $34.1 \%$ of the 41 patients and $8.1 \%$ of the 172 patients, 11 cases of viral origin (26.8\%) and 16 cases for which the cause has not been identified although they all had a history of recurrent otorhinolaryngologic infections and/or urinary schistosomiasis;

- chronic tubulointerstitial nephropathy: 26 cases (19.4\%);

- polycystic kidney disease: two cases (1.5\%).

\subsection{The Beginning Circumstances of Hemodialysis}

The hemodialysis started in an emergency context in 118 cases (68.6\%). The 54 remaining cases (31.4\%) were planned hemodialysis.

One hundred sixty-two patients representing $94.2 \%$ of the cases started the hemodialysis with a central venous catheter (CVC). Among the 10 others (5.8\%), the first hemodialysis session was done with an arteriovenous fistula.

\subsection{Vascular Access Situations of Patients}

At the time of the study, 164 patients (95.3\%) had a CVC at least one time. The average number of CVCs received per patient was $3.5 \pm 2.2$ (extremes $=1$ and 20). This number was:

- between 1 and 3:106 patients (64.6\%);

- between 4 and 5:34 (20.7\%);

- between 6 and 10:19 (11.6\%);

- greater than 10:5 (3.1\%).

An arteriovenous fistula was created at least once in 157 patients (92.3\%). We observed a primary dysfunction of the first fistula in 38 cases over the 157 cases (24.2\%). The average number of fistulas created per patient was $1.4 \pm 0.7$ (extremes $=1$ and 5 ).

\subsection{Duration in Hemodialysis}

At the time of the study, the average duration of hemodialysis patients was $29.4 \pm 28.4$ months (extremes $=3$ and 162). This duration was distributed as follows:

$-\leq 12$ months: 55 patients (32\%);

-13 to 48 months: 81 patients (47.1\%);

- $\geq 49$ months: 46 patients (26.7\%).

\section{Discussion}

The recommended frequency of hemodialysis sessions is three per week. At the time of our study, with 29 posts for hemodialysis, the hemodialysis unit of the UHC-YO couldn't ensure such a program; regardless of the insufficiency of human and financial resources. The solution would be to increase the number of generators in the 
city of Ouagadougou and open a unit for example in the West of the country. This solution involves at least the availability of human resources in sufficient number; which is not yet the case. The insufficiency of hemodialysis center coverages is a general problem in Africa, especially in the Sub-Saharan part [4].

The national prevalence of treated ESRD is low, compared to those of 154 and 370 pmp respectively in France and the United States [7]. In reality the result that we report is underestimated because all patients of the interior part of the country with ESRD cannot reach the department of Nephrology and Hemodialysis of the UHC-YO. In addition, a significant number of patients admitted to this department for ESRD have no access to hemodialysis for various reasons including the lack of financial resources. The patients were men in $61.6 \%$. Our results are comparable to other African studies that report a frequency of male of at least $60 \%$ [8] [9]. Patients in our study were young (45.2 \pm 12.4 years), like those of other African countries where the average age varies between 43 and 50 years [10] [11]. It is an economically productive group of the population which activity is forcefully reduced due to the sub-optimal treatment conditions. In contrast, in developed countries, the average age of patients is usually greater than 60 years [7]. Nearly half of the patients in our study had no employment, were farmers or retired. In a context where the costs of drugs and tests are entirely charged to the patient, this can be a problem for a good adherence to treatment and follow-up of these patients. The high cost of drugs was pointed out by Seck et al. in Senegal as a factor favoring the non-compliance to treatment in patients with chronic kidney disease [12]. However, the solidarity of the community of origin of these patients is not without limit; when this runs out, the patient is let in a state of extreme poverty. Developing countries engaging in a chronic hemodialysis program should fund enough care in order to provide patients with better productivity conditions.

We could not identify the presumed nephropathy in $22.1 \%$ of cases. This is not surprising because on one hand, more than a third of patients reach the department only at the final stage of CRF, and on the other hand, the diagnostic tests were limited.

Among the presumed causes of ESRD, hypertension and CGNs were the most frequent in our study. These are usually the first cause of CRF in Africa [9] [10] [13]. In our context where patients arrive at a late stage, the role of hypertension in renal dysfunction may be difficult to establish. The risk is to overestimate its frequency among the causes of renal dysfunction. In all cases, its good control is a major objective to achieve not only for the protection of the kidneys before the final stage of CRF, but also for the secondary prevention of cardiovascular complications in hemodialysis patients. This goal is however difficult to achieve in our hemodialysis unit due to the limitation of resources for the unit and patients.

The CGNs came in second place as a cause of CRF in our patients. It is a common cause in the sub-Saharan Africa countries. Thus, in Africa countries such as Nigeria and Sudan where it is the second cause after hypertension, its frequency is $27.8 \%$ and $17.6 \%$, respectively [9] [14]. In Ghana, CGNs remain the first cause of CRF with a frequency of $33 \%$ reported in a hospital study [15]. The causes of these CGNs in our study seem to be mainly infectious if we consider the high frequency of history of ORL sphere infections and the results of the study of Lengani et al. in the same hospital [16]. This study of Lengani et al. led to identify infections as a first cause of CRF with a frequency of $42.5 \%$. The prevalence of nephropathy related to HIV as a cause of ESRD is growing in sub-Saharan Africa [17].

Diabetes in our study was a less common cause of ESRD. However, its place among the causes of ESRD seems growing in Burkina Faso. Indeed, the study of Lengani et al. in 1997 noted only two cases of diabetes among 174 patients with severe CRF [16]. This disease, which prevalence is growing worldwide, is the first cause of ESRD in developed countries [18], and the second in more and more sub-Saharan Africa countries [10] [19] [20]. In this part of Africa, the prevalence among hemodialysis patients varies from one region to another. Thus, it goes from 6.1\% in Ethiopia to 23.8\% in Zambia [2]. Diabetes and hypertension are diseases with an increasing prevalence in the general population, which is favored among other by a modern lifestyle characterized by sedentary lifestyle and a diet too often salted or sweet. They are modifiable factors which taken into consideration would contribute to the reduction of the prevalence of CRF.

The majority of our patients (94.2\%) started their first session of dialysis with a central venous catheter. This rate is very high and explains on one hand various difficulties to create arteriovenous fistula in advance for patients followed up before the final stage and on the other hand the delayed first contact of patients with the department of Nephrology and Hemodialysis. Sanogo in Bamako found a comparable rate of $97.4 \%$ and encounters the same difficulties in the management of his patients [21]. Even in developed countries, patients are treated late and have to begin the hemodialysis with a CVC. In France in 2011, 33\% of patients started their di- 
alysis session in an emergency situation and 56\% with a CVC [22].

The average number of CVCs per patient was particularly high. This is due to a delay in patients treatment, a long waiting time (94.5 days in 2011, 72.3 in 2014 [23] [24]), and a lack of equipment for the repair of fistula [24]. The long waiting time is in part due to a deficiency in human resources, the limited availability of the operating room for the creation of fistulas at the UHC-YO and difficulties related to patients to pay the fees for the creation of the fistula.

\section{Limitations of the Study}

Most of the data were gathered from patient medical records. The quality and quantity of the information contained therein depend on the writer who could be an intern or a doctor (general practitioner or nephrologist). It can be noted the absence of some paraclinical data (including anatomopathological) related mainly to the lack of equipment or economic difficulties at the level of the patients. These limitations have not prevented us from describing the UHC-YO hemodialysis unit patients and drawing interesting information.

\section{Conclusion}

Our study reported the difficult conditions of treatment in the unique hemodialysis unit located in Ouagadougou, the capital of Burkina Faso. The patients are mostly young. The most frequently encountered causes of chronic kidney disease are hypertension and chronic glomerular nephropathy. The latest seems to be more often related to bacterial or viral infections than diabetes. The treatment of end-stage renal disease needs to be sufficiently funded to meet the standards; this could be achieved by innovative modes of financing. Its prevention should focus on hypertension, and infectious diseases in the general population of Burkina Faso.

\section{Conflict of Interest}

None.

\section{References}

[1] Grassmann, A., Gioberge, S., Moeller, S. and Brown, G. (2005) ESRD Patients in 2004: Global Overview of Patient Numbers, Treatment Modalities and Associated Trends. Nephrology Dialysis Transplantation, 20, 2587-2593. http://dx.doi.org/10.1093/ndt/gfi159

[2] Naicker, S. (2009) End-Stage Renal Disease in Sub-Saharan Africa. Ethnicity \& Disease, 19, 13-15.

[3] Vanholder, R., Lameire, N., Annemans, L. and Van Biesen, W. (2015) Cost of Renal Replacement: How to Help as Many as Possible While Keeping Expenses Reasonable? Nephrology Dialysis Transplantation, Published Online.

[4] El Matri, A. (2015) ESRD Management in Africa during the Last Decade. Clinical Nephrology, 83, 11-13. http://dx.doi.org/10.5414/CNP83S011

[5] Touam, M., Orozco, R., Fumeron, C., Ganea, A., Drücke, T. and Grünfeld, J.-P. (2001) Refractory Ascites in Hemodialysis: Treatment by Puncture-Reinjection during Dialysis. Nephrology, 22, 25-28.

[6] Pei, Y., Obaji, J., Dupuis, A., Paterson, A.D., Magistroni, R., Dicks, E., et al. (2009) Unified Criteria for Ultrasonographic Diagnosis of ADPKD. Journal of the American Society of Nephrology, 20, 205-212. http://dx.doi.org/10.1681/ASN.2008050507

[7] Lassalle, M., Ayav, C., Frimat, L., Jacquelinet, C. and Couchoud, C. (2015) au nom du Registre REIN. The Essential of 2012 Results from the French Renal Epidemiology and Information Network (REIN) ESRD Registry. Néphrologie \& Thérapeutique, 11, 78-87. http://dx.doi.org/10.1016/j.nephro.2014.08.002

[8] Kabbali, N., S Mikou El Pardiya, N., El Bardai, G., Arrayhani, M. and Houssaini, T.S. (2014) Profile of Chronic Hemodialysis in Diabetics: Multicentric Study in Morocco. The Pan African Medical Journal, 17, 125.

[9] Banaga, A.S.I., Mohammed, E.B., Siddig, R.M., Salama, D.E., Elbashir, S.B., Khojali, M.O., et al. (2015) Causes of End Stage Renal Failure among Haemodialysis Patients in Khartoum State/Sudan. BMC Research Notes, 8, 502. http://dx.doi.org/10.1186/s13104-015-1509-X

[10] Okunola, Y., Ayodele, O., Akinwusi, P., Gbadegesin, B. and Oluyombo, R. (2013) Haemodialysis Practice in a Resource-Limited Setting in the Tropics. Ghana Medical Journal, 47, 4-9.

[11] Ekrikpo, U.E., Udo, A.I., Ikpeme, E.E. and Effa, E.E. (2011) Haemodialysis in an Emerging Centre in a Developing Country: A Two Year Review and Predictors of Mortality. BMC Nephrology, 12, 50. 
http://dx.doi.org/10.1186/1471-2369-12-50

[12] Seck, S.M., Elhadj, F.K., Fall, S., Cissé, M.M., Dia, D., Guèye, S., et al. (2008) Adherence to Therapy in Sub-Saharan Non-Dialysed Patients with Chronic Kidney Diseases. Néphrologie \& Thérapeutique, 4, 325-329. http://dx.doi.org/10.1016/j.nephro.2008.02.004

[13] Diouf, B., Ka, E.F., Niang, A., Diouf, M.L., Mbengue, M. and Diop, T.M. (2000) Etiologies of Chronic Renal Insufficiency in an Adult Internal Medicine Service in Dakar. Dakar Medical, 45, 62-65.

[14] Arogundade, F., Sanusi, A., Hassan, M. and Akinsola, A. (2011) The Pattern, Clinical Characteristics and Outcome of ESRD in Ile-Ife, Nigeria: Is There a Change in Trend? African Health Sciences, 11, 594-601.

[15] Amoako, Y.A., Laryea, D.O., Bedu-Addo, G., Andoh, H. and Awuku, Y.A. (2014) Clinical and Demographic Characteristics of Chronic Kidney Disease Patients in a Tertiary Facility in Ghana. The Pan African Medical Journal, 18, 274.

[16] Lingani, A., Coulibaly, G., Laville, M. and Zech, P. (1997) Epidemiology of Severe Chronic Renal Insufficiency in Burkina Faso. Santé, 7, 379-383.

[17] Madala, N.D., Thusi, G.P., Assounga, A.G. and Naicker, S. (2014) Characteristics of South African Patients Presenting with Kidney Disease in Rural KwaZulu-Natal: A Cross Sectional Study. BMC Nephrology, 15, 61. http://dx.doi.org/10.1186/1471-2369-15-61

[18] Jin, D.C., Yun, S.R., Lee, S.W., Han, S.W., Kim, W., Park, J., et al. (2015) Lessons from 30 Years’ Data of Korean End-Stage Renal Disease Registry, 1985-2015. Kidney Research and Clinical Practice, 34, 132-139. http://dx.doi.org/10.1016/j.krcp.2015.08.004

[19] Seck, S.M., Doupa, D., Gueye, L. and Dia, C.A. (2014) Prevalence of Chronic Kidney Disease and Associated Factors in Senegalese Populations: A Community-Based Study in Saint-Louis. Nephro-Urology Monthly, 6, e19085.

[20] Halle, M.P., Takongue, C., Kengne, A.P., Kaze, F.F. and Ngu, K.B. (2015) Epidemiological Profile of Patients with End Stage Renal Disease in a Referral Hospital in Cameroon. BMC Nephrology, 16, 59. http://dx.doi.org/10.1186/s12882-015-0044-2

[21] Sanogo, A. (2015) Study of Vascular Access in Hemodialysis in the Nephrology Department of the National Hospital of Point G in Mali. Thesis Medicine, No. 56, University of Mali, Bamako, 2005-2006 Academic Year, 89 p.

[22] Kolko, A., Dueymes, J.M., Couchoud, C. and registre du REIN (2013) Baseline Characteristics and Indicators of Support for New Dialysis Patients in 2011. Néphrologie \& Thérapeutique, 9, S65-S94. http://dx.doi.org/10.1016/S1769-7255(13)70040-3

[23] Souro, S.O. (2011) Arteriovenous Fistulas in Chronic Hemodialysis Patients at the UHC-YO: About 75 Cases. Thesis Medicine, No. 046, University of Ouagadougou, Ouagadougou, 2010-2011 Academic Year, 64 p.

[24] Oubda, N.R. (2014) Epidemiological and Evolutionary Aspects of the Native Radial Arteriovenous Fistulas for Chronic Hemodialysis at the UHC-YO. Thesis Medicine, No. 043, University of Ouagadougou, Ouagadougou, 2013-2014 Academic Year, 75 p. 